\title{
The Role of Open Source Communities in Development: Policy Implications for Governments
}

\author{
Georg J.P. Link \\ University of Nebraska at Omaha \\ glink@unomaha.edu
}

\author{
Sajda Qureshi \\ University of Nebraska at Omaha \\ squreshi@unomaha.edu
}

\begin{abstract}
Open Source Software (OSS) communities engage in a shared design of software that meets the needs of community members. This dynamic may have a positive influence on development by enabling the growth of micro-enterprises thus offering opportunities for governments to stimulate their growth. This paper explores the connection between OSS communities and development outcomes to arrive at a theoretical framework that enables the investigation of the role of OSS communities in development. By examining existing government policies, we find that policymakers recognize the potential for OSS communities to create shared value through private-collective innovation. In understanding the transformative role of OSS, this research investigates (1) how OSS communities contribute to development efforts and (2) how government policy can stimulate development efforts through OSS. The contribution of this paper is in the policy implications for governments on how they may use OSS to drive development.
\end{abstract}

\section{Introduction}

In his sequel to "creating a better world" with ICTs, Walsham [49] suggests that new ICT-enabled models can transform the processes and structures of development. An example of a new ICT-enabled model is the use of open source software (OSS) in a variety of contexts, including disasters, conflicts, and emergencies [27]. OSS is popular with the ICT4D community because it helps make a difference and is transformative in enabling people at all levels of society to participate and see what is happening in their own context.

OSS communities provide platforms for anyone to participate in the development of software solutions that are then made accessible to everyone. The main characteristic of an OSS is the open source license, which builds on copyright law and gives everyone the right to use for any purpose, modify the software, and share the software without charge [29]. This legal openness is complemented with a development process that is public where online communities coordinate the creation of software.

Compared to proprietary software, whose development is constrained by the resources of a single organization, OSS development has the potential to scale by incorporating the work of many [16]. The OSS development builds on the idea to separate out the development work into small manageable tasks that volunteers can accomplish independently [24]. Complex and challenging problems in a software are deferred until smaller subproblems are solved and together solve the bigger problem.

This OSS development process is gaining traction with organizations [4] and governments. One reason for the increasing popularity of OSS is the ability for organizations to innovate at faster rates and in collaboration with otherwise competitors [17]. This innovativeness of OSS is rooted in the collaboration mechanisms that are built on the belief that the development process cannot be planned in the light of unknown potential contributions from developers [16]. These mechanisms allow for faster adaptability to market changes and to better meet the needs of the people as testing and deployment cycles are shorter and involve many contributors.

OSS offers innovations for low resource environments such as frugal innovations [43, 51]. Frugal innovations are 'good-enough' for a particular purpose and affordable by reducing a product to its essential elements that meet people's needs at the lowest possible cost. The source of frugal innovations is local research and development efforts that understand the local needs and transform them into low-cost products [51]. The best people to engage in frugal innovation are entrepreneurs that come from the low-resource environments that the innovation is meant for. For example, Walsham [49] specifically pointed out health as a special topic to engage in and there are several OSS communities in the health space. GNU Health (http://health.gnu.org/), for example, provides a software with functions for electronic 
medical records, hospital management, and health information system to be used by health practitioners, health institutions, and governments.

Innovative uses of ICTs, such as GNU Health, can bring about improvements in people's lives. A recent study [35] investigated the relationship between OSS participation, new business formation and development outcomes, through unemployment rates. The study found a positive correlation between new business formation and active OSS developers, which was statistically significant. Development was found in the positive relationship between job creation with business formation and OSS participation [35]. This paper responds to the call for research into the complexities involved in how OSS is linked to development outcomes. We develop a theoretical framework that can help answer the following research questions:

RQ1: How can open source software contribute to development?

RQ2: How can government policy stimulate development through open source software?

\section{Methodology}

The use of ICTs by NGOs, small and mediumsized enterprises has been shown to enable growth, particularly through sustained technology and training interventions [28, 45]. Micro, small, and medium enterprises (SME), as well as Social Enterprises and NGOs appear to be at the heart of efforts to understand the effects of ICTs on Development and are the main unit of analysis for this study.

While the definition of these forms of organization varies between countries, SMEs are more efficient at creating quality jobs, are more innovative, or grow faster than larger firms [19]. Seen as a form of small business, social enterprises and NGOs are also key players in enabling ICT usage to support better livelihoods. Their activities offer non-profit earned income which in turn provides consistent cash flow to further the mission of the organization [36].

This research follows an inductive approach. To answer the first research question, a literature review is carried out to identify concepts and propositions which illustrate the relationships between the concepts. Following Lee and Baskerville's [32] TT approach to generalizing from concepts to theory, this research involves generalizing concepts of shared value, engagement, and private-collective innovation to create a theoretical framework. This is then clarified in a thought experiment [25] of how these microenterprises engage in OSS communities to grow and bring about development. The outcomes from the adoption of ICT on development can be assessed in a number of ways. The measures of economic development in micro-enterprises most often used are: increase in income, jobs, and clientele [44]. Additional human development outcomes relate to better livelihoods, life expectancy, and access to needed resources.

Governments play an important role in stimulating development through policies. The second research question is investigated using a data set of 354 government OSS policies from all over the world. These are analyzed using the concepts from the theory using an open coding technique to identify the extent to which these concepts and relationships can be identified in the data [8]. From the results of the analysis, we arrive at policy implications for governments on how they may stimulate development through OSS.

We follow the example of the World Bank and will not distinguish between developed and developing countries and economies [13]. This outdated classification is still deeply engrained in our thinking and the associated issues are well documented [31]. The United Nation avoids these issues in the Sustainable Development Goals by setting goals for the world. For this reason, we treat all countries and economies unbiased and with the same respect by avoiding artificial classifications.

\section{Theoretical Background}

\subsection{ICT4Development}

The role of ICTs in bringing about development has been the subject of a great deal of research and practice. Harris [21] argues that much of the research in ICT for Development fails the poor as it ignores the ways in which the activities may in fact lead to socioeconomic impact of the projects they study. Others have argued that research in ICT4D involves the interaction of policy makers, practitioners and researchers to understand the effects of ICTS on development outcomes [47, 49]

Walsham [49] proposes that researchers should engage with users, practitioners, and policy-makers through communities of practice on particular themes and issues. OSS communities are such communities of practice that develop software for a specific purpose. OSS can have a positive influence on development, through its inclusive and open nature [16].

The concept of development outcomes can be grouped into three dimensions: economic, social, and human [37]. This paper focuses on understanding a development outcome, economic development, but 
recognizes the interconnection between all three dimensions. The concept of economic development has its roots in the economics of the firm. Economic development was defined by Schumpeter as "changes in economic life as are not forced upon it from without but arise by its own initiative, from within" [9:141] with the understanding that development is different from the normal business cycle by characterizing "spontaneous and discontinuous change in the channels of the flow, disturbance of equilibrium, which forever alters and displaces the equilibrium state previously existing" [9:141]. In other words, Schumpeter viewed development as rooted in entrepreneurial activities that disturb current equilibria through innovation to bring about new equilibria.

Entrepreneurs produce new combinations of products and services that satisfy customers' needs. As such, entrepreneurs fulfill the needs of other people and improve their lives [20]. Subsequent development comes from two processes: (1) entrepreneurs can grow their business from a micro-enterprise of fewer than ten employees to larger organizations that employ more people and provide more products and services to more customers, and (2) entrepreneurs can save profits and invest in their children who will be better educated and better equipped to take on challenges in the future [20]. Ultimately, entrepreneurial activity enables people to enlarge their choices which is related to a long and happy life, education, and a decent standard of living [37]. In summary, entrepreneurs and their micro-enterprises are important mechanisms of development [5].

\subsection{Shared Value}

When entrepreneurs make decisions that are to benefit their micro-enterprise and benefit their local community, then they create shared value [41]. In the past, business was perceived as only interested in maximizing profits and disregarding the impact on the environment and local community. Porter and Kramer [41] proposed to solve this problematic view by focusing on creating shared value, which occurs through policies and operating practices that enhance the competitiveness of a micro-enterprise while simultaneously advancing the economic and social conditions in the local community. Research shows that this approach can raise the well-being of entire communities [33]. For example, a local farmer and entrepreneur provided services to other farmers and helped them be more productive through soil sampling and giving farming related advice [26]. The entrepreneur profited from providing the service and the customers increased their returns from harvests and became wealthier. By responding to new needs of the clients, the entrepreneur provided new services and through the ongoing innovation continued to create shared value.

\subsection{ICT4D in Micro-Enterprises}

Information and communication technology (ICT) enables government, business, and personal activities [47]. How ICT influences global development has been subject to research for over thirty years [49]. For ICT to impact development, issues related to readiness, availability, and uptake have to be addressed [22].

Micro-enterprises are important in assessing development outcomes from their use of ICT. Without ICT, they rely on localized, informal social networks for often poor quality information and knowledge which limits their influence on social and economic development [12]. ICT has been reported to cause positive outcomes such as business growth, increased productivity, administrative efficiencies, increased revenues, improved marketing strategies, better access to customers, and cost saving [3, 44].

The use of ICT in micro-enterprises can improve sales growth by 3.4 percentage points (i.e., $3.8 \%$ vs. $0.4 \%$ ) and their profitability by 5.1 percentage points (i.e., 9.3\% vs. 4.2\%) [42]. Initially, existing microenterprises might not have seen the benefit of bringing ICT into their firm and only adopted ICT because of social pressure [46]. At times, micro-enterprises that want to adopt ICT might lack technical skills or cannot afford the investment in technology [44]. Nevertheless, many entrepreneurs are seeking to upgrade their ICT because they see the benefits of being better connected with customers and having access to timely information [11].

In the context of ICT supported businesses, Roztocki and Weistroffer [47] proposed a conceptual framework, in which business activities and services are enabled by ICT, supported by human and social capital, and generated in an environment of governmental policies, business culture, and existing infrastructure. Through the use of ICT, microenterprises become more efficient, create more value, and affect development even more [47]. With the spread of internet, micro-enterprises gain access to online resources including OSS. Because OSS can be used for free, it enables micro-enterprises to try it out and build new services and products on top of it. The increasing use of ICTs, often through OSS, has brought about the rise of "micro-multi-national enterprises" that sell arts and crafts and offer services such as virtual assistance, software maintenance, and development. 


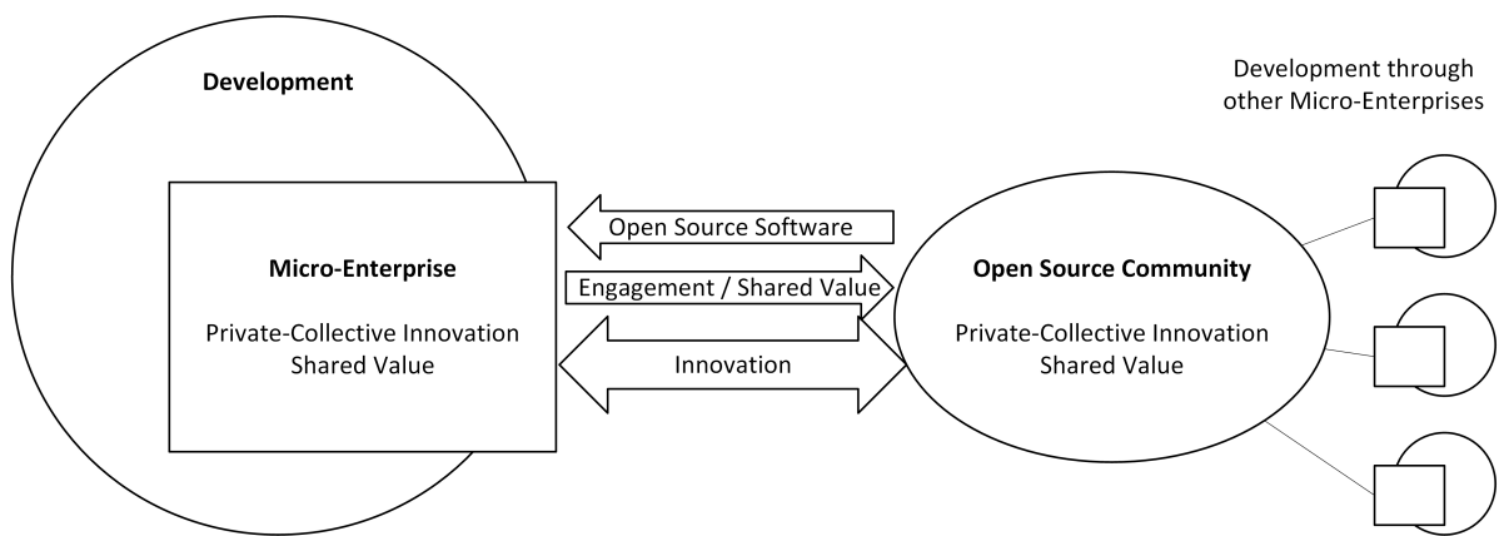

Figure 1: Theoretical framework MEDOSS depicts the relationship between OSS communities as a source of innovation for micro-enterprises that impact development in local communities.

\subsection{Private-Collective Innovation}

Micro-enterprises have the benefit of being generally more innovative than large corporations, which gives them a competitive advantage [5]. The source of innovations has been studied in many areas and one recent trend is to consider open innovation [6]. This new paradigm limits the constraint that an innovation has to come from within an organization by realizing that an exchange of ideas and creative solutions occurs with customers, vendors, employees, and other stakeholders. Chesbrough's [6] open innovation model posits the organization as the main actor that takes in ideas from outside and refines them in traditional research and development activities. A more collaborative and open approach is the privatecollective innovation method that is prevalent in OSS development [23]. The name indicates that the innovation is driven by private interests but owned by the collective.

The roots of the OSS movement are grounded in the desire to make software a public good that everyone can freely share and modify [29]. In recent years, OSS is dominated by organizations [30]. Organizations integrate OSS in their own innovation and development practices [18]. The technology that is developed in OSS communities does not provide a competitive advantage and as such competitors can engage in the same community to advance a nondifferentiating technology together [17]. Organizations typically pay employees to engage and make sure the community aligns with the strategic goal of the organization [10]. These tendencies resulted in OSS communities becoming more stabilized, forward planning, and strategic so that organizations can rely on the community [14]. Some communities have evolved into networks of organizations that provide complementary products and services around the same OSS and can build on each other if needed when responding to a customer need [15]. A benefit of OSS is that anyone can start using it for free and still add potential value because they might become contributors later or add value by spreading the word [7].

Entrepreneurs can create shared value through OSS by collaboratively creating and sharing new products and services. By combining their innovation efforts with others in OSS communities, entrepreneurs can tap into the expertise of an entire community. The innovation model is known as private-collective innovation where the micro-enterprise expands private resources for innovation and shares it with the community, making it public while benefiting from the public contributions of others [23].

\section{Theoretical Framework: MEDOSS}

Roztocki and Weistroffer [47] proposed that ICT supported business activities and services impacts development. Our framework builds on this idea, outlining that micro-enterprises can build on OSS to create shared value for the micro-enterprise, the local community that it is rooted in, and the OSS community. For innovation purposes around OSS, the micro-enterprise can engage in a private-collective innovation with OSS communities. Which communities the micro-enterprise wants to engage in depends on the business needs that the OSS can fulfill. When engaging in the private-collective innovation, the micro-enterprise creates shared value for itself and the OSS community. The OSS community can serve several micro-enterprises and other organizations that use the innovation and contribute to it, driving development in multiple locations. We name our theoretical framework MEDOSS - Micro-Enterprise Development with Open Source Software. See figure 1 for a graphical depiction of the framework. 


\subsection{Thought Experiment}

To illustrate our theoretical framework MEDOSS, we present a thought experiment: Imagine your neighbor Nia to be a web-developer. Nia is running a micro-enterprise that creates websites for its customers, including the local church, the pub around the corner, and the restaurant down the street. Nia is a typical entrepreneur, does not have any employees, and does all the development work herself. To speed up the development, Nia is looking for existing solutions to create a website and found WordPress, an OSS blogging and content management system for websites. Nia compares WordPress to other solutions and likes that WordPress is open source which allows her to use it for free and make changes as needed. Another positive that Nia likes about WordPress is the vibrant OSS community of developers who help improve WordPress and develop many plugins that enhance the features of websites built with WordPress. After making sure that WordPress meets her business needs, Nia starts building websites for her customers with WordPress.

For the restaurant down the street, Nia uses a basic setup and a design that another developer had freely shared under an OSS license. The restaurant wants its business hours and current menu on the website and be able to change anything themselves without asking Nia for help. WordPress provides all this. Nia simply combined the content for the restaurant with the OSS WordPress.

The pub around the corner has live music every Friday and Saturday and wants people to vote on its website on which bands or artists to invite. WordPress does not include a voting feature but Nia goes to the large repository of freely available plugins that developers have created to enhance WordPress and finds one that does exactly what the pub wants. Nia combines the content of the pub with WordPress and the voting plugin to create the website.

The local church wants its members to sign up for volunteer opportunities and one volunteer coordinator to manage a schedule. Nia does not find a WordPress plugin that does what the church requested and so develops her own plugin. She combines the new plugin with WordPress and the content of the church. Then, Nia releases her new plugin under an OSS license and lists it on the WordPress community website. Another developer finds Nia's volunteer management plugin and uses it for an after-school program website. The school likes the plugin very much and asks for the plugin to support all after-school programs. The school's developer enhances the plugin to support this new use case better and contributes those changes back to Nia's original volunteer
Table 1: Regional distribution of OSS Government Policies [34].

\begin{tabular}{|l|c|c|c|c|}
\hline Region & Approved & Proposed & Failed & Total \\
\hline Europe & 126 & 27 & 10 & 163 \\
\hline Asia & 59 & 20 & 2 & 81 \\
\hline $\begin{array}{l}\text { Latin } \\
\text { America }\end{array}$ & 31 & 15 & 11 & 57 \\
\hline $\begin{array}{l}\text { North } \\
\text { America }\end{array}$ & 16 & 11 & 10 & 37 \\
\hline Africa & 8 & 1 & 0 & 9 \\
\hline $\begin{array}{l}\text { Middle } \\
\text { East }\end{array}$ & 5 & 2 & 0 & 7 \\
\hline Total & 245 & 76 & 33 & 354 \\
\hline
\end{tabular}

management plugin. Nia likes the enhancement and uses the new version for her church website which now can manage their choir, youth group, and any other group with volunteer opportunities through their website.

This thought experiment demonstrated the MEDOSS mechanisms. Nia observed the WordPress community to judge whether it was the right fit for her need to develop websites. Nia engaged with the community in two ways: by using the software, and secondly by contributing her own plugin. Nia innovated in combining WordPress with the needs of her customers and creating their website. By sharing her innovation of the volunteer management plugin, she engaged in private-collective innovation and created shared value for her business, the church, and the high school that started using her plugin. In return, the school's developer enhanced the innovation and Nia's church directly benefited from the OSS development model in the WordPress community.

\section{Analysis: OSS Government Policies}

In this section, data from a total of three hundred and fifty-four OSS policy initiatives [34] is analyzed using the theoretical framework MEDOSS developed above. The dataset contains policy initiatives until 2010 but was the most recent compilation we could locate. The dataset is sufficient for applying MEDOSS. Further, a more recent (2015) summary of government policies aligns with the findings we present below [50] - indicating that policy changes in the past years would not change the conclusions we can draw. The regional distribution of the data is illustrated in Table 1.

Many policies made the use of OSS in government agencies recommended, mandatory, or an equivalent option to proprietary software. A common driver is a lower cost of ownership compared to proprietary software, which governments argue is a responsible use of tax money. Another major driver is 
Table 2: Labels that emerged from open coding and exemplar quotes to illustrate concepts.

\begin{tabular}{|l|l|l|}
\hline Concept & Labels & Exemplar Quote \\
\hline Innovation & $\begin{array}{l}\text { Open source } \\
\text { engagement, } \\
\text { Open standards }\end{array}$ & $\begin{array}{l}\text { The France Ministry of Defense "has formed a consortium to develop a highly secure Linux- } \\
\text { based operating system." }\end{array}$ \\
\hline $\begin{array}{l}\text { Shared value, } \\
\text { Coordination } \\
\text { between } \\
\text { governments, } \\
\text { Public benefit }\end{array}$ & $\begin{array}{l}\text { The Russian Ministry on Information Technology and Communications aims "to strengthen the } \\
\text { local software development industry and increase involvement of Russian programmers in the } \\
\text { development of software for government and municipal needs" }\end{array}$ \\
\hline $\begin{array}{l}\text { Development- } \\
\text { Education }\end{array}$ & $\begin{array}{l}\text { School, } \\
\text { Training }\end{array}$ & $\begin{array}{l}\text { Tunisia's "objectives included encouraging migration to FOSS, including FOSS in school } \\
\text { curricula, providing incentives to FOSS company start-ups, and ensuring that public procurement } \\
\text { policies are not biased against FOSS." }\end{array}$ \\
\hline $\begin{array}{l}\text { Development- } \\
\text { Employment }\end{array}$ & $\begin{array}{l}\text { Independence, } \\
\text { Private public } \\
\text { partnership }\end{array}$ & $\begin{array}{l}\text { Singapore "offers tax breaks to companies that use GNU/Linux operating systems instead of } \\
\text { proprietary ones to encourage development of the local software sector." }\end{array}$ \\
\hline
\end{tabular}

interoperability between government agencies and citizens. Open standards take a central role in promoting the use of OSS, although proprietary software can also support open standards.

With regards to the above introduced MEDOSS framework, the government policy initiatives addressed shared value, innovation, and encouraging micro-enterprises to engage in OSS development. Some policies encourage micro-enterprises to use and develop OSS by direct financial incentives. Using a set of 354 government open source policies from all over the world, open coding was carried out to identify the extent to which these concepts and relationships can be identified in the data. Table 2 illustrates the results from open coding.

\subsection{Private-Collective Innovation}

Thailand, for example, set itself the goal to become a leading center for OSS development and allocated a budget of about US\$1.5 million to encourage OSS development. Taiwan pledged US\$3.4 million into promoting OSS development.

A Thailand specific version of the OSS operating system Linux was actively developed by the government and distributed to the people. China, India, and Catalonia also actively maintain and distribute localized Linux versions for their government agencies and people.

\subsection{Shared Value}

Some policies were directly aimed at fostering a dialog between the government and the people. Russia, for example, approved to "increase involvement of Russian programmers in the development of software for government and municipal needs" which is to be achieved through “competence centers". Some governments established platforms for exchange of experience with OSS. This is evidence of private-collective innovation between governments and the people. One such example is Govsolvers, an OSS community for e-government in Colombia [39]. The U.S.A. maintains the platform Code.gov. The EU has the Open source observatory ${ }^{1}$.

\subsection{Development Outcomes - Education}

Another way governments promoted more OSS development within their countries is by educating and developing the skills of its people. Catalonia pledged 50,000 Euro to develop OSS professionals. Argentina's Ministry of Labor approved a privatepublic collaborative program that trained citizens in open technologies. Education on OSS starts in schools where some governments require OSS to be installed and used. Some initiatives even get OSS into the hands of students by distributing USB-sticks or CDs with OSS and including OSS in the school curriculum.

\subsection{Development Outcomes - Employment}

These initiatives have the goal to improve the national software industry and create more local employment. Argentina's rationale for promoting Linux was to "create local employment". Argentina, Brazil, China, France, Russia, South Korea, and Spain enacted a policy each to promote OSS "to spur national industry". Bolivia not only targeted to "advance the local software industry", but also to "promote alternatives to transnational monopolies." The goal to "avoid dependency on proprietary systems" or on companies in other countries was obvious in several policies, including from Cambodia, Costa Rica, Cuba, France, Italy, Norway, Pakistan, and Russia.

\footnotetext{
${ }^{1}$ https://joinup.ec.europa.eu/community/osor/home
} 


\section{Discussion: Policy Implications for Governments}

The above analysis has shown that governments are playing an important role in stimulating OSS to achieve development outcomes. Several different policy approaches were observed, targeting various development outcomes, specifically education and employment. At that same time, government efforts focus on offering ICT infrastructure to underserved communities with little focus on build ICT capabilities. Few governments foster innovative uses of OSS by micro-enterprises. This innovativeness can enable increased competitiveness, growth in enterprises, and the economy in large [5]. We highlighted OSS engagement as one source of innovativeness.

Efforts by local or regional governments to ensure adequate ICT skill and training programs enable micro-enterprises' to use OSS to bring about growth. When micro-enterprises in a community or region can see growth from OSS and better-trained people that they can hire, growth for the communities and regions in which they reside can take place.

Increased transparency afforded by OSS projects in governments can reduce corruption at the national level and consequently at the local level in the interaction with businesses and citizens because wrongdoers will more likely be held accountable [48]. Government legislation, processes, and responsibilities are made more publicly available. This enables citizens to uncover abuse of power within political, legal, and media institutions. Corruption is linked to lower levels of ICT capacity in a country which impedes on the positive effects that ICT may have [2]. Offering incentives for OSS use can reduce corruption in governments and increase transparency of its operations.

The protection of property rights is an important element of development. The availability of OSS ICT systems should be paired with policies supporting open exchange of information and innovations. Strict intellectual property laws can adversely affect access to not only OSS but also medicines and public health in low-resource nations [40]. Owoeye [40] argues for a development-oriented approach for implementing intellectual property laws that will "enhance local pharmaceutical innovation, easier access to essential drugs, and human development" (p. 232). On a related subject, open access provides free access to research publications and thereby attempts to make knowledge more widely available [1]. Rather than hoping that information made available is leveraged by local communities, people can be involved in solution finding and innovation processes.
A surprising finding is the important role of open standards in promoting OSS. Our MEDOSS framework did not predict to find open standards in OSS policies. Open standards do not put restrictions on the use of the standard, e.g. through trade secrets or patents, similar to how OSS ensures freedom to use OSS for any purpose. Governments demand open standards to be supported by software to ensure interoperability between government agencies and the people. Open standards also reduce vendor lock-in and provides a level playing field for OSS and proprietary software, ensuring freedom of choice and enabling innovation. Policy makers who find it challenging to lobby for OSS may find it easier to lobby for open standards because it does not exclude existing software vendors but only pushes them to openness.

The policy implications are brought together through our MEDOSS framework which outlines the complexities involved in the development process. Policies must account for the interplay of the concepts in MEDOSS. The overarching implication for policy makers is to balance policies across the above outlined policy approaches. A focused policy in one area, e.g. including OSS in school-curricula, may not unfold its full potential if not complemented with related policies, e.g. supporting micro-enterprise engagement with OSS.

\section{Conclusion}

The first contribution is MEDOSS, our theorydriven framework which provides a way to begin understanding how government policies regarding OSS can translate to development through microenterprises. We found support for our framework through the analysis of existing government policies regarding OSS.

The second contribution is policy implications. Governments have at least five options for fostering development through supporting OSS and the main policy implication is to strive for a balanced approach amongst: 1) develop and use OSS themselves, 2) require OSS to receive a fair chance in sourcing decisions, 3) provide a legal framework for ensuring OSS licenses work, e.g. software patents, copyright law, 4) invest in OSS development through direct funding or tax benefits, and 5) promote the private use of OSS e.g. distribute software to citizens or install OSS on school computers. An additional, indirect policy option is to require open standard support in software used by government agencies.

This paper responded to a call to understand the complexities involved in how OSS is linked to development outcomes [35]. Our theoretical MEDOSS framework and the policy implications 
advanced our understanding. Next, we provide ideas for future research that can deepen our understanding.

First, while this research identified policy implications for governments to drive development by fostering OSS, future research can unpack the specific effects of policies and determine which OSS policy options are the most effective for stimulating growth in micro-enterprises. A possible extension to MEDOSS could involve a distinction between microenterprises that engage in the OSS community and those who only use OSS, which in turn can be compared to users of proprietary software. Cultural differences and availability of skills in an economy could be moderating factors. An interesting perspective might come from OSS communities who directly observe the impact of policies and involvement of micro-enterprises.

Second, we decided to analyze the data without the artificial classification of developed and developing countries. Future research could investigate whether clusters of countries emerge with regards to their effectiveness of policies.

Third, this paper theorized a causal impact of OSS policies on OSS development and consequently on growth in micro-enterprises. The legal and political environment likely influences the degree to which micro-enterprises can engage in OSS communities. Future research may test the counter hypothesis that policies for growing micro-enterprises lead to more OSS development and that OSS policies are only an indicator for micro-enterprise friendly environments.

Fourth, we developed MEDOSS first and applied it in analyzing existing policies. Future research may work the reverse and use grounded theory to arrive at implications based on existing policies.

A limitation is that the dataset is from 2010 and does not contain recent events, such as the Munich City Council's 2017 decision to return to proprietary software after several years of investing in an OSS environment for its administration [38]. Another limitation is the data's inability to demonstrate actual impact which we leave for future research.

\section{ORCID iD}

\section{Georg J.P. Link (iD orcid.org/0000-0001-6769-7867}

\section{References}

[1] Ahmed, A., "Open access towards bridging the digital divide-policies and strategies for developing countries," Information Technology for Development 13(4), 2007, pp. 337-361.
[2] Andoh-Baidoo, F.K., B. Osatuyi, and K.N. Kunene, "ICT capacity as the investment and use of ICT: Exploring its antecedents in Africa," Information Technology for Development 20(1), 2014, pp. 44-59.

[3] Bharati, P., and A. Chaudhury, "SMEs and competitiveness: The role of information systems," International Journal of E-Business Research; Hershey 5(1), 2009, pp. i-ix.

[4] Black Duck, "The tenth annual future of open source survey," Black Duck Software, 2016. https://www.blackducksoftware.com/2016-future-ofopen-source

[5] Bošković, G., L. Savić, and V. Mićić, "Innovation as a determinant of competitiveness and development of small and medium-sized enterprises in the Republic of Serbia," TEME: Casopis za Društvene Nauke 40(1), 2016, pp. 171-185.

[6] Chesbrough, H., "Open innovation: A new paradigm for understanding industrial innovation," In H. Chesbrough, W. Vanhaverbeke and J. West, eds., Open Innovation: Researching a New Paradigm. Oxford University Press, 2006.

[7] Cranefield, J., P. Yoong, and S. Huff, "Rethinking lurking: Invisible leading and following in a knowledge transfer ecosystem," Journal of the Association for Information Systems 16(4), 2015, pp. 213-247.

[8] Creswell, J.W., Qualitative inquiry and research design: Choosing among five approaches, SAGE Publications, Los Angeles, 2013.

[9] Croitoru, A., "Schumpeter, JA, 1934 (2008), The theory of economic development: An inquiry into profits, capital, credit, interest and the business cycle," Journal of Comparative Research in Anthropology and Sociology 3(2), 2012, pp. 137-148.

[10] Dahlander, L., and M.W. Wallin, "A man on the inside: Unlocking communities as complementary assets," Research Policy 35(8), 2006, pp. 1243-1259.

[11] Donner, J., "Internet use (and non-use) among urban microenterprises in the developing world: an update from India," Conference of the Association of Internet Researchers (AoIR), (2006), 28-30. 
[12] Duncombe, R., and R. Heeks, "Enterprise across the digital divide: Information systems and rural microenterprise in Botswana," Journal of International Development 14(1), 2002, pp. 61-74.

[13] Fantom, N., T. Khokhar, and E. Purdie, "The 2016 edition of World Development Indicators is out: Three features you won't want to miss," The Data Blog, 2016. http://blogs.worldbank.org/opendata/2016-editionworld-development-indicators-out-three-featuresyou-won-t-want-miss

[14] Feller, J., P. Finnegan, B. Fitzgerald, and J. Hayes, "From peer production to productization: A study of socially enabled business exchanges in open source service networks.," Information Systems Research 19(4), 2008, pp. 475-493.

[15] Fitzgerald, B., "The transformation of open source software," MIS Quarterly 30(3), 2006, pp. 587598.

[16] Garzarelli, G., Y.R. Limam, and B. Thomassen, "Open source software and economic growth: A classical division of labor perspective," Information Technology for Development 14(2), 2008, pp. 116135.

[17] Germonprez, M., J.P. Allen, B. Warner, J. Hill, and G. McClements, "Open source communities of competitors," ACM Interactions 20(6), 2013, pp. 5459.

[18] Germonprez, M., J.E. Kendall, K.E. Kendall, L. Mathiassen, B. Young, and B. Warner, "A theory of responsive design: A field study of corporate engagement with open source communities," Information Systems Research 28(1), 2016, pp. 64-83.

[19] Gibson, T., and H.J. Van der Vaart, Defining SMEs: A less imperfect way of defining small and medium enterprises in developing countries, Brookings Global Economy and Development, 2008.

[20] Grosh, B., and G. Somolekae, "Mighty oaks from little acorns: Can microenterprise serve as the seedbed of industrialization?," World Development 24(12), 1996, pp. 1879-1890.

[21] Harris, R.W., "How ICT4D research fails the poor," Information Technology for Development 22(1), 2016, pp. 177-192.
[22] Heeks, R., "Do information and communication technologies (ICTs) contribute to development?," Journal of International Development 22(5), 2010, pp. 625-640.

[23] von Hippel, E., and G. von Krogh, "Open source software and the 'private-collective' innovation model: Issues for organization science," Organization Science 14(2), 2003, pp. 209-223.

[24] Howison, J., and K. Crowston, "Collaboration through open superposition: A theory of the open source way," MIS Quarterly 38(1), 2014, pp. 29-A9.

[25] Introna, L.D., and E.A. Whitley, "Imagine: Thought experiments in information systems research," Proceedings of the IFIP TC 8 WG 8.2 International Conference on Information Systems and Qualitative Research, Chapman \& Hall, Ltd., 1997, 481-496.

[26] Jha, S.K., A. Pinsonneault, and L. Dubé, "The evolution of an ICT platform-enabled ecosystem for poverty alleviation: The case of eKutir," MIS Quarterly 40(2), 2016, pp. 431-446.

[27] Jones, C., and S. Mitnick, "Open source disaster recovery: Case studies of networked collaboration," First Monday 11(5), 2006.

[28] Kamal, M., and S. Qureshi, "Sustaining the growth of micro-enterprises that adopt information and communication technologies," Proceedings of the Second Annual Workshop on Global Development, 2009.

[29] Kelty, C.M., Two bits: The cultural significance of free software, Duke University Press, Durham, 2008.

[30] Kelty, C.M., “There is no free software," Journal of Peer Production(3), 2013.

[31] Khokhar, T., and U. Serajuddin, "Should we continue to use the term "developing world'?," The Data Blog, 2015. http://blogs.worldbank.org/opendata/should-wecontinue-use-term-developing-world

[32] Lee, A.S., and R.L. Baskerville, "Generalizing generalizability in information systems research," Information Systems Research 14(3), 2003, pp. 221243. 
[33] Leong, C., S.L. Pan, S. Newell, and L. Cui, "The emergence of self-organizing e-commerce ecosystems in remote villages of China: A tale of digital empowerment for rural development," MIS Quarterly 40(2), 2016, pp. 475-A8.

[34] Lewis, J.A., Government Open Source Policies, Center for Strategic and International Studies, 2010.

[35] Link, G.J.P., and S. Qureshi, “The role of open source in new business formation: Innovations for development," Proceedings of the Twenty-third Americas Conference on Information Systems, 2017.

[36] Lyons, T.S., J. Townsend, A.M. Sullivan, and T. Drago, "Social Enterprise's Expanding Position in the Nonprofit Landscape," 2010. http://staging.community-

wealth.org/sites/clone.communitywealth.org/files/downloads/paper-lyons.pdf

[37] Malaquias, R.F., F.F. de O. Malaquias, and Y. Hwang, "The role of information and communication technology for development in Brazil," Information Technology for Development 23(1), 2017, pp. 179 193.

[38] Meyer, D., "Linux flagship Munich's U-turn: Install Windows 10 everywhere by end of 2020," ZDNet, 2017. http://www.zdnet.com/article/linuxflagship-munichs-u-turn-install-windows-10everywhere-by-end-of-2020/

[39] Moreno, L.M.M., J.O.T. Páez, and J.S. Mogrovejo, "Govsolvers: An open source community for e-government in Colombia," Proceedings of the 9th International Conference on Theory and Practice of Electronic Governance, ACM, 2016, 342-345.

[40] Owoeye, O., "Intellectual property, health, regionalism and development: A third world's perspective," European Journal of Sustainable Development 5(4), 2016, pp. 225-232.

[41] Porter, M., and M.R. Kramer, "Creating shared value," Harvard Business Review 89(1/2), 2011, pp. $1-17$.

[42] Qiang, C.Z.-W., G.R. Clarke, and N. Halewood, "The role of ICT in doing business," In Information and communications for development - Global trends and policies. The World Bank, Washington, DC, 2006.
[43] Qureshi, S., "Driving development through innovations in information technology and its applications," Information Technology for Development 16(4), 2010, pp. 241-243.

[44] Qureshi, S., M. Kamal, and P. Wolcott, "Information technology interventions for growth and competitiveness in micro-enterprises," International Journal of E-Business Research; Hershey 5(1), 2009, pp. 117-140.

[45] Qureshi, S., M. Kamal, and P. Wolcott, "Information technology interventions for growth and competitiveness in micro-enterprises," In P. Bharati, A. Chaudhury and I. Lee, eds., Global Perspectives on Small and Medium Enterprises and Strategic Information Systems: International Approaches. IGI Global, New York, 2010, 306-329.

[46] Riemenschneider, C.K., D.A. Harrison, and P.P. Mykytyn, "Understanding it adoption decisions in small business: Integrating current theories," Information \& Management 40(4), 2003, pp. 269-285.

[47] Roztocki, N., and H.R. Weistroffer, "Conceptualizing and researching the adoption of ICT and the impact on socioeconomic development," Information Technology for Development 22(4), 2016, pp. 541-549.

[48] Srivastava, S.C., T.S.H. Teo, and S. Devaraj, "You can't bribe a computer: Dealing with the societal challenge of corruption through ICT," MIS Quarterly 40(2), 2016, pp. 511-A9.

[49] Walsham, G., "ICT4D research: reflections on history and future agenda," Information Technology for Development 23(1), 2017, pp. 1-24.

[50] Wheeler, D.A., "Why open source software / free software (OSS/FS, FOSS, or FLOSS)? Look at the numbers!," 2015. https://www.dwheeler.com/oss_fs_why.html

[51] Zeschky, M., B. Widenmayer, and O. Gassmann, "Frugal innovation in emerging markets," ResearchTechnology Management 54(4), 2011, pp. 38-45. 